International Journal of Social Science and Economic Research

ISSN: 2455-8834

Volume: 05, Issue: 04 "April 2020"

\title{
SUBSTANCE, SOCIETY, STIGMA: ASSESSING THE RESPONSE TO DRUG ABUSE INTERVENTIONS IN INDIA
}

\author{
Tarini Sehgal \\ Pathways School Gurgaon \\ DOI: 10.46609/IJSSER.2020.v05i04.012 URL:https://doi.org/10.46609/IJSSER.2020.v05i04.012
}

\begin{abstract}
$18 \%$ of the total burden of diseases in the world is attributed to the use of psychoactive substances including prescription drugs, alcohol, tobacco, and illicit drugs. Substance abuse is defined as the patterned use of a substance that leads to dependence, the degradation of physical and mental health, and harm to society. Governments across the world, especially in developing countries have failed to tackle this growing public health crisis that not only targets vulnerable sections of the society but also adds to the economic burden the people and the state are forced to bear. This paper has explored the reasons behind the failure of subsequent central and state governments in India to deal with the growing rates of substance abuse in the country. The lack of understanding of the physiological aspects of dependence and abuse and its characterization as a 'choice' has hampered the ability of the state to introduce holistic policies. Needle exchange programs and long term rehabilitation facilities have been found to be key in the fight against substance abuse because the basis for engagement with those affected by substance abuse is their characterization as 'victims' of state failure and not as criminals. Through a comprehensive analysis of policies introduced in the west, this paper has sought to provide policy recommendations aimed at improving the lives of the most vulnerable communities that are affected by the substance abuse pandemic.
\end{abstract}

Keywords: Substance abuse, Drugs, Healthcare, Mental health, Government

\section{INTRODUCTION}

Substance abuse is defined as the patterned use of a substance in which the user consumes the substance in amounts or with methods that are harmful to themselves or others. The understanding of what constitutes 'substance abuse' is imperative to study it in different contexts (Jenkins, 1999). 'Substances' that have been historically associated with abuse' include illegal 


\section{International Journal of Social Science and Economic Research}

ISSN: $2455-8834$

Volume: 05, Issue: 04 "April 2020"

drugs and alcohol- specifically, cocaine, heroin, and methamphetamines. However, research suggests that the substances that have become most likely to be abused in the twenty-first century constitute prescription drugs. 'Abuse' refers to the consumption of substances at a rate which either makes the individual physiologically or psychologically dependent on them or it leads to an adverse effect on the well being of individuals or those around them.

Substance abuse represents a growing problem in the twenty-first century. In 1990, the world witnessed 165,000 deaths due to substance abuse. This number grew to 307,400 by 2015 (Wang, et. al., 2015). The increasing prevalence of substance abuse across the world can be attributed to general changes in the global economic and political environment. Globalization has led to the global availability of ideas and commodities, including illegal intoxicants. The deep web has enabled the growth of a growing black market for substances that governments across the world have failed to control. However, the most acute public health crises associated with substance abuse in the past decade - such as the Opioid Epidemic of the United States of America are not attributed to the usage of illegal drugs but due to the increased availability of prescription drugs to individuals. This increased availability is a result of the lack of regulation over the healthcare industry which holds immense lobbying power across the world (Mohamadi, et. al., 2018). This manifests in the form of overprescription on part of doctors, the easy availability of drugs and the lack of general oversight at the hands of the government. After alcohol disorders which are responsible for the most number of substance abuse fatalities at 137,500 people annually, opioid use disorders are responsible for 122,100 deaths, almost ten times those of amphetamine use disorders (12,200 deaths), and cocaine use disorders (11,100 deaths) (Wang, et. al., 2015). Substance abuse not only constitutes a public health crisis but is associated with negative socioeconomic outcomes in the short and long term. Substance abuse directly impacts the organs of individuals causing diseases including hepatitis, liver disease, HIV and cancer. Injected drug users account for $10 \%$ of all HIV cases in the world (National Health Portal, 2017). Drug abusers and alcoholics are more likely to be suicidal, and 30\% - 40\% of suicides in America have been associated with drug or alcohol abuse (Isralowitz. 2004). The prolonged use of substances has an adverse impact on the mental health of individuals as well, causing acute depression, anxiety, and schizophrenia. Research also suggests that those who use intoxicants regularly are more likely to commit homicides, sexual assault and motor vehicle accidents which suggests that those in the vicinity of addicts are often the worst victims of substance abuse (Burke, et. al., 2005).

In India, the most commonly abused substances include heroin ( commonly known as brown sugar) and pharmaceutical opioids such as Buprenorphine, Pentazocine, and DextroPropoxyphene. $7.2 \%$ of those affected by HIV AIDS in India has been reported to be dependent on injectable substances (National Health Portal, 2017). Substance abuse represents nothing short of social and public health crisis in developing countries India- putting a significant section 


\section{International Journal of Social Science and Economic Research}

ISSN: $2455-8834$

Volume: 05, Issue: 04 "April 2020"

of the country's youth at risk of addiction and related diseases. Even though substance abuse is often characterized by physiological or psychological dependence on a particular substance, the problems that individuals and society face as a result of it can be mitigated through different policy interventions. Substance Abuse Prevention is a process that attempts to prevent the onset of substance use or limit the development of problems associated with using psychoactive's substances. Prevention efforts focus on the individual or their surroundings. Environmental prevention focuses on changing community conditions, supply-side policies seek to reduce the availability of substances whereas targeted interventions are aimed at victims of substance abuse. Research suggests that state intervention is instrumental in reducing substance abuse at the community level (Copeman, 2003). Moreover, given that substance abuse is a product of social failure, it is the inherent burden of welfare states to formulate and implement interventions that seek to reduce the impact of this pandemic.

\section{BACKGROUND}

The misconceptions that surround substance abuse in developing countries have been responsible for the lack of adequate state interventions. These are often fueled by the lack of understanding

of the physiological aspects of substance abuse and addiction, which often leads to the phenomenon being characterized as a personal choice. This, in turn, contributes to the state and society shrugging off their burden of creating an environment free of factors that facilitate abuse. The physical and psychological changes that the body goes through as a result of substance abuse are dependent on the substance in question. Physical dependence develops from low-dose therapeutic use of certain medications such as benzodiazepines, opioids, antiepileptics and antidepressants, and recreational misuse of alcohol, and amphetamines (Landry, et. al., 1992). The degree of physical dependence is directly proportional to high drug doses, and a longer duration of usage. Unpleasant withdrawal symptoms that often manifest in criminal behavior are common when drugs are taken away from victims of addiction. It is also reported that others have strong cravings even after they have not used the drug for a long period of time (Aldhous, 2009). The management of physical dependency is a slow process that often lasts for weeks, with the social surroundings of the victim often determining the recovery. These substance-related disorders, that are characterized by cravings are classified as a subcategory of personality disorders in the DSM-5 (American Psychiatric Association, 2013).

Substance abuse and addiction Drug shares many commonalities with other chronic illnesses, including a tendency to be heritable through genes, an onset and course that is influenced by environmental conditions and behavior, and the ability to respond to appropriate treatment, which may include long-term lifestyle modification. The characterization of substance abuse as a disease is key in directing state and social action. Evidence from adoption and twin studies have 


\section{International Journal of Social Science and Economic Research}

ISSN: $2455-8834$

Volume: 05, Issue: 04 "April 2020"

demonstrated that addiction, like other chronic diseases, is a heritable disorder and that genes play an important role in determining the vulnerability of individuals to addiction (NIDA, 2010). However, environmental factors also determine the rate of substance abuse epidemics in different communities. Childhood trauma or abuse often drives adolescents to experiment with intoxicants, which often develops into an addiction. Other factors like the lack of a classroom environment, parental negligence, mental illness and high rates of substance abuse in the vicinity are considered to be the primary environmental factors for substance addiction in India (National Health Portal, 2017). The perception of medication that society has, at different points in time also determines risk levels. For example- the Opioid Crisis in the United States began with overprescription of opioids in the 1990s, that was fueled by the demands of organizations like the Joint Commission of more attentive and active responses of physicians to patient pain. Pharmaceutical organizations often benefit financially from substance addiction such as Opioid Epidemics (Baker, 2017). This legitimizes demands for increased state intervention in the market for prescription drugs.

\section{DISCUSSION}

Certain sections of the population have been found to be more vulnerable and susceptible to substance abuse. It is found to be greatest in individuals aged 18-25, with a higher likelihood occurring in men compared to women (with the exception of Opioids), and urban residents compared to rural residents (Leikin, 2007). Contextualizing epidemics and identifying groups that are at higher risk of developing an addiction is considered to be key in developing interventions. Immigrants are considered to be critical groups in the fight against substance abuse in India and across the world. Immigrants often face a high level of stress (due to the fear of unemployment and deportation), physical trauma and depression and anxiety due to separation from their homelands and the "cultural dissonance" they face in host countries, that is characterized by language barriers, racism, discrimination, economic adversity, overcrowding, social isolation, and loss of status. Intoxicating substances are often used by them as a coping mechanism to attempt to deal with these stressors (Rothe, et. al., 2005). Moreover, they are likely to introduce newer substances and abuse patterns to the local populace, hence making them vulnerable too (Clark, et. al., 1998). Indian states that are located at the eastern and western border such as Punjab have faced some of the most dangerous substance abuse epidemics in recent years, which many attributes to the lack of control over borders and unchecked immigration (Sharma, 2017). A study conducted on 400 adolescents and young adults aged 1135 years in Punjab shows a high likelihood of individuals developing heroin addiction (21\%).

Homelessness has been a growing problem in India since the economic liberalization of 1991, which was followed by mass waves of immigration from rural to urban areas of these countries. 


\section{International Journal of Social Science and Economic Research}

ISSN: $2455-8834$

Volume: 05, Issue: 04 "April 2020"

The lack of availability of housing and employment opportunities has resulted in a significant section of migrants being rendered homeless. The homeless, especially homeless children have been at the center of the debate surrounding the reduction of substance abuse and addiction in India in recent years. The report suggests that there are more than one hundred thousand homeless children in each of the metropolitan cities of India (Naik, et. al., 2011). Substances do not only function as a coping mechanism for homeless children but are also a contributing factor to homelessness. Substances are often at the center of most economic activity for homeless children, as substance peddling is a means of income for many and substances are often used as relief against stressors. Research conducted on street children in Bombay suggests that the reasons behind substance abuse can be traced to frustration concerning living on the street or conflicts in their family which have caused them to leave home (Kombarakaran, 2004). Research conducted in Kenya suggests that in the absence of adequate state intervention, substance abuse emerges as a link to the support structure of the 'street family' peer group as a potent symbol of shared experience (Cottrell-Boyce, 2010). When the need for validation and belongingness amongst homeless children is not fulfilled by the state and society, it further pushes them into substance abuse and related behavior. Even though substance abuse is a social problem that faces the whole of India at large, nuances in geographical distribution are important to be accounted for in order to develop effective interventions and policy. In the north-eastern of India, heroin and dextropropoxyphene are the most commonly used substances, whereas impure heroin (smack), and buprenorphine are most commonly used in metropolitan cities such as Delhi, Mumbai, Chennai, and Kolkata. Pentazocine is the most commonly injected opioid in Karnataka, Andhra Pradesh, Chattisgarh whereas the primary cause for concern in Punjab and Haryana is buprenorphine (National Health Portal, 2017).

The state response to the public health crisis surrounding substance abuse in India has been inadequate, which has put a significant section of the country's youth at risk (Singh \& Gupta, 2017). The major drug laws of India are the Narcotic Drugs and Psychotropic Substances Act (1985) and the Prevention of Illicit Trafficking in Narcotic Drugs and Psychotropic Substances Act (1988). Through subsequent amendments, the central government of India has produced a list of 'controlled substances', the usage or trade of which results in punishment that includes imprisonment - lasting up to 20 years (The Gazette of India, 2014). This reveals a fundamental flaw in the understanding of substance abuse in Indian society due to its characterization as a 'choice' and not a 'disease'. This allows the government to prosecute substance abusers in a way similar to how other criminals are prosecuted- ignoring the biopsychological and social aspects of substance abuse. Moreover, this has prevented subsequent central and state governments from developing rehabilitation programs and facilities for victims of substance abuse and that burden has been shifted to the not for profit and private sector entirely. The primary reason behind the lack of development of correctional facilities and rehabilitation centers in India is the absence of 


\section{International Journal of Social Science and Economic Research}

ISSN: $2455-8834$

Volume: 05, Issue: 04 "April 2020"

state investment. Moreover, the perception of drug abuse as an individual choice leads to the villainization of victims and reluctance in accessing rehabilitation facilities. The Indian State has also been reluctant in introducing needle exchange programs even though they have proven to be significantly successful in the west (Wodak \& Coney, 20004).

The Drug Policy of India seeks to control the trade and usage of intoxicants and drugs not commonly available in the market, which leads to increased emphasis on supply-side policies that seek to regulate the inflow and trade of prohibited substances. However, the abuse of substances available in the market for other purposes has largely been ignored. For example- the substances most abused by homeless children in India are inhalants, which are available in the market as whiteners or adhesives. Policies seeking to prevent the consumption of these substances are absent at the central and state level which has led to these problems being dealt with inefficiently by local governments and the police, which is often ignorant of the medical aspect of substance abuse altogether. Similarly, even though India provides for a minimum legal age for consuming alcohol and tobacco, these provisions are very selectively implemented. The lack of effective regulation has led to high rates of consumption of alcohol and tobacco amongst minors in India- which often takes the form of abuse and addiction in the long run. This either happens as a direct dependence or addiction to alcohol or tobacco or indirectly, since these substances often act as a gateway to other intoxicants and controlled substances (Singh \& Gupta, 2017).

\section{CONCLUSION}

Substance abuse represents one of the most critical challenges to not only the governments, public officials and healthcare systems, but also the Indian society. The quality of interventions and policies implemented by a state is often a response to social narratives and perceptions. The lack of awareness surrounding substance abuse and its subsequent characterization as a choice has led to the villainization of victims, most of whom qualify for the diagnosis of certain mental illnesses. There is a need to increase research and awareness around the psychological and physiological aspects of substance abuse in India, not only to better the quality of interventions but also to enhance the sensitivity of the society towards victims and dispel myths that surround substance abuse in India. Alongside supply oriented policies that aim at reducing the availability of substances, governments should invest in measures that reduce the loss of life caused due to substance abuse through investing in rehabilitation facilities and needle exchange programs, both of which have been associated with reducing mortality rates of victims of substance abuse (Wodak \& Cooney, 2004). Research conducted by Nguyen, et. al., concludes that needle exchange programs are a more cost-efficient intervention for HIV outbreaks as compared to treatment (Nguygen, et. al., 2015) Research suggests that family, school and community-based 


\section{International Journal of Social Science and Economic Research}

ISSN: $2455-8834$

Volume: 05, Issue: 04 "April 2020"

prevention programs lead to increased awareness about the social and individual harms of substance abuse and reduce the propensity of consumption of substances, especially amongst the youth (Boat, et. al., 2009).

Substance abuse often takes the shape of epidemics because it affects entire communities at once, similar to the ongoing Opioid Crisis in the United States of America. Healthcare costs associated with substance abuse strain individual and state economic resources. Individuals who are victims often demonstrate anti-social behavior, are more likely to commit crimes and are generally less productive. Over $50 \%$ of individuals with substance-related disorders often have a "dual diagnosis," where they are diagnosed with substance abuse, as well as a psychiatric diagnosis including major depression, personality disorder, anxiety disorders, and dysthymia (Leikin, 2007). India's response to this pandemic has been limited and short-sighted which has made some of the most vulnerable sections of the population more susceptible to addiction and substance abuse. The formulation and implementation of holistic interventions are dependent not only on the economic resources at the disposal of the state but also on narratives that surround substance abuse in society since they often direct the allocation of resources. It is imperative to change the regressive mainstream narratives around substance abuse in India and sensitize communities through scientific research and grassroots level awareness campaigns in an attempt to facilitate quality interventions and improve the lives of those affected by substance abuse.

\section{BIBLIOGRAPHY}

Aldhouse, P. (2009). Drug binge' mice reveal why cravings linger. Newscientist. Accessed 29th March 2020

American Psychiatric Association. (2013). Diagnostic and Statistical Manual of Mental Disorders - Fifth Edition. Accessed on 29th March 2020

Baker, D.W. (2017). The Joint Commission's Pain Standards: Origin and Evolution. Accessed on 31st March 2020

Boat, T., O'Connell, M.E., Warner, K.E. (2009). Preventing Mental, Emotional, and Behavioral Disorders Among Young People: Progress and Possibilities. Committee on the Prevention of Mental Disorders and Substance Abuse Among Children, Youth and Young Adults: Research Advances and Promising Interventions. Institute of Medicine; National Research Council. Accessed on 1st April 2020

Burke, P.J., O'Sullivan, J., Vaughan, B.L. (2005). Adolescent substance use: brief interventions by emergency care providers. Pediatr Emerg Care. Accessed on 30th March 2020 
International Journal of Social Science and Economic Research

ISSN: 2455-8834

Volume: 05, Issue: 04 "April 2020"

Clark, C. L., Tam, T., Caetano, R. (1998). Alcohol consumption among racial/ethnic minorities: Theory and research. Journal of Alcohol, Health, and Research. Accessed on 1st April 2020

Copeman, M. (2003). Drug supply and drug abuse. Accessed on 30th March 2020

Cottrell-Boyce, J. (2010). The role of solvents in the lives of Kenyan street children: An ethnographic perspective. African Journal of Drug \& Alcohol Studies. Accessed on 1st April 2020

Kombarakaran, F.A.. (2004). Street children of Bombay: their stresses and strategies of coping. Children and Youth Services Review. Accessed on 29th March 2020

Isralowitz, Richard (2004). Drug use: a reference handbook. Accessed on 30th March 2020

Leikin, J.B. (2007). Substance-Related Disorders in Adults. Disease-a-month. Accessed 29th March 2020

Mohamadi, A., Chan, J.J., Lian, J., Wright, C.L., Marin, A.M., Rodriguez, E.K., von Keudell, A., Nazarian, A. (2018). Risk Factors and Pooled Rate of Prolonged Opioid Use Following Trauma or Surgery: A Systematic Review and Meta-(Regression) Analysis. The Journal of Bone and Joint Surgery. American Volume. Accessed on 30th March 2020

National Institute of Drug Abuse (2010). Drug Abuse and Addiction: One of America's Most Challenging Public Health Problems. Accessed on 31st March 2020

National Health Portal. (2017). Substance Abuse. Government of India, Accessed on 31st March 2020

Naik, P.R., Bansode, S.S., Shinde, R.R., Nirgude, A.S. (2011). Street children of Mumbai: demographic profile and substance abuse. Biomedical Research. Accessed on 29th March 2020

Nguyen, T.Q., Weir, B.W., Des Jarlais, D.C., Pinkerton, S.D, Holtgrave, D.R. (2015). Syringe Exchange in the United States: A National Level Economic Evaluation of Hypothetical Increases in Investment. Aids and Behavior, Accessed on 4th April 2020

Rothe, E., Pumariega, J. B.,Pumariega, A. J. (2005). Mental health of immigrants and refugees. Community Mental Health Journal. Accessed on 31st March 2020 
Sharma, R. (2017). Drug abuse: Uncovering the burden in rural Punjab. Journal of Family Medicine and Primary Care. Accessed on 1st April 2020

Singh, J., Gupta, P. (2017). Drug Addiction: Current Trends and Management. International Journal of Indian Psychology. Accessed on 29th March 2020

The Gazette of India. (2014). The Narcotic Drugs and Psychotropic Substances (Amendment) Act, 2014. Ministry of Law and Justice, Government of India. Accessed on 1st April 2020

Wang, H., et. al. (2015). Global, regional, and national life expectancy, all-cause mortality, and cause-specific mortality for 249 causes of death, 1980-2015: a systematic analysis for the Global Burden of Disease Study 2015. GBD 2015 Mortality and Causes of Death Collaborators. Accessed on 29th March 2020

Wodak, A., Cooney, A. (2004). Effectiveness of Sterile Needle and Syringe Programming in Reducing HIV/AIDS Among Injecting Drug Users. World Health Organization. Accessed on 29th March 2020 